\title{
RECURRENT INTRA NASAL GLIOMA: A CASE REPORT
}

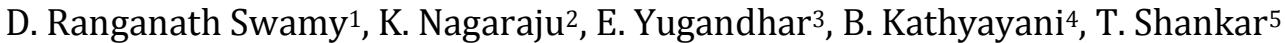

\section{HOW TO CITE THIS ARTICLE:}

D. Ranganath Swamy, K. Nagaraju, E. Yugandhar, B. Kathyayani, T. Shankar. "Recurrent Intra Nasal Glioma: A Case Report". Journal of Evolution of Medical and Dental Sciences 2015; Vol. 4, Issue 64, August 10;

Page: $11247-11252$, DOI: $10.14260 /$ jemds/2015/1620

ABSTRACT: Nasal gliomas are rare congenital mild-line tumors often misdiagnosed as encephalocele, midline dermoid. Nasal gliomas constitute about $5 \%$ of congenital midline swellings. Imaging preferably by MRI is mandated to study the extent and to rule out intracranial extension. The gold standard treatment is surgical excision and histo-pathological confirmation. We present a case of recurrent intranasal glioma without any intracranial extension presented as swelling in the nose, excised by lateral rhinotomy approach.

KEYWORDS: Encephalocele, Hemangioma, Lateral rhinotomy, Nasal glioma, Nasal dermoid.

INTRODUCTION: Nasal gliomas are rare, benign, congenital masses more accurately referred as sequestered glial tissue,(1) three types of clinical presentation have been recognized.

\section{Types of nasal gliomas:}

*Extra nasal (60\%) - lies external to the nasal bones and nasal cavity.

*Intra nasal (30\%) - Found within the nasal or nasopharyngeal cavity.

*Combined (10\%) - consists of a communication between the extranasal and intranasal components.

These are one of the congenital midline masses a category which also includes nasal dermoids and encephaloceles.(2) The nasal glioma first described by Schmidt in 1900.(3,4) The reported incidence is 1 in every 20,000 to 40,000 births, (5) histologically they are made up of astrocytic neuroglial cells, fibrous and vascular connective tissue that is covered with naso-respiratory mucosa. The treatment of these masses is surgical excision which requires a multidisciplinary approach including a radiologist, neurosurgeon and otorhinolaryngologist. Although rare, these disorders are clinically important because as their potential for connection to the central nervous system.(6)

CASE REPORT: A 2 Years male child, presented with chief complaints of (R) side nasal obstruction, which was progressive on set. No history of bleeding from nose, disturbance in smell and epistaxis.

On Examination: Anterior rhinoscopy-smooth, soft to firm, single mass seen in (R) Nasal cavity, filling entire nasal cavity, no bleeding on touch, patient was subjected for investigations, all the investigations were within normal limits.

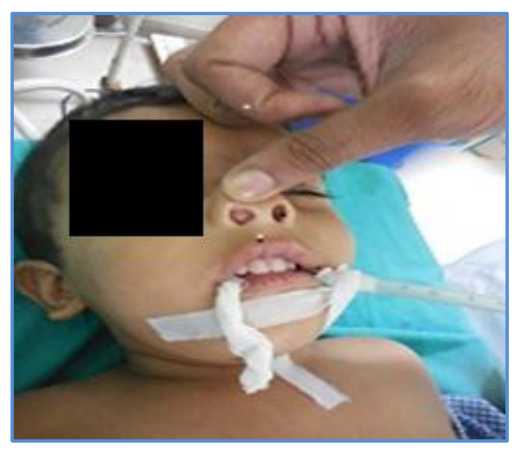

Fig. 1: Clinical Photo (Preoperative) 


\section{CASE REPORT}

History of nasal surgery for same problem 1year back, which was done externally by incision over the dorsum of the nose, HPE reported as nasal glioma.

CT scan Report (Fig. 2): A Well-defined lobulated heterogenous lesion with hyperdense and hypodense components in the anterior portion of right nasal cavity, with hypodense component appears to continue intracranially through a small defect of $1 \mathrm{~mm}$ between crista galli and frontal crest (Fonticulus nasofrontalis) - findings may suggest glial heterotopias (Nasal glioma).
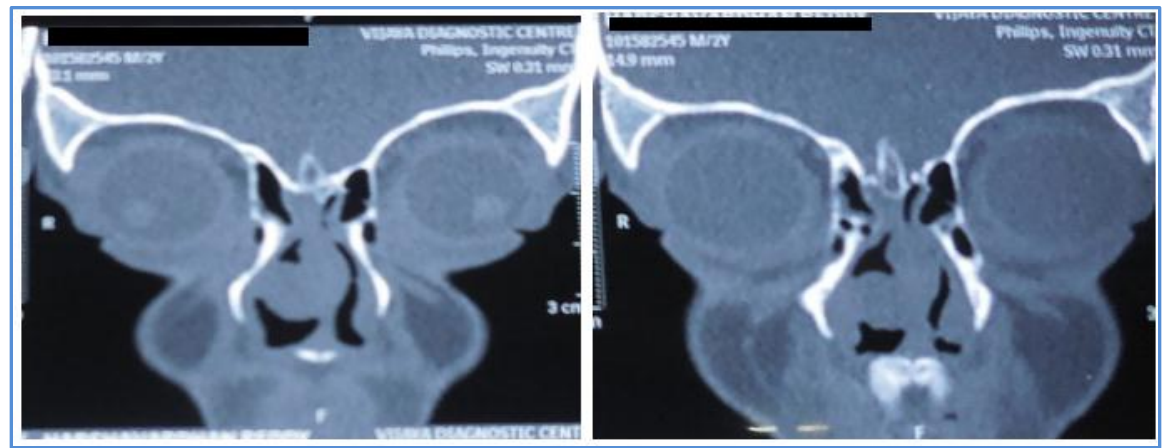

Fig. 2a \& 2b: CT scan photos
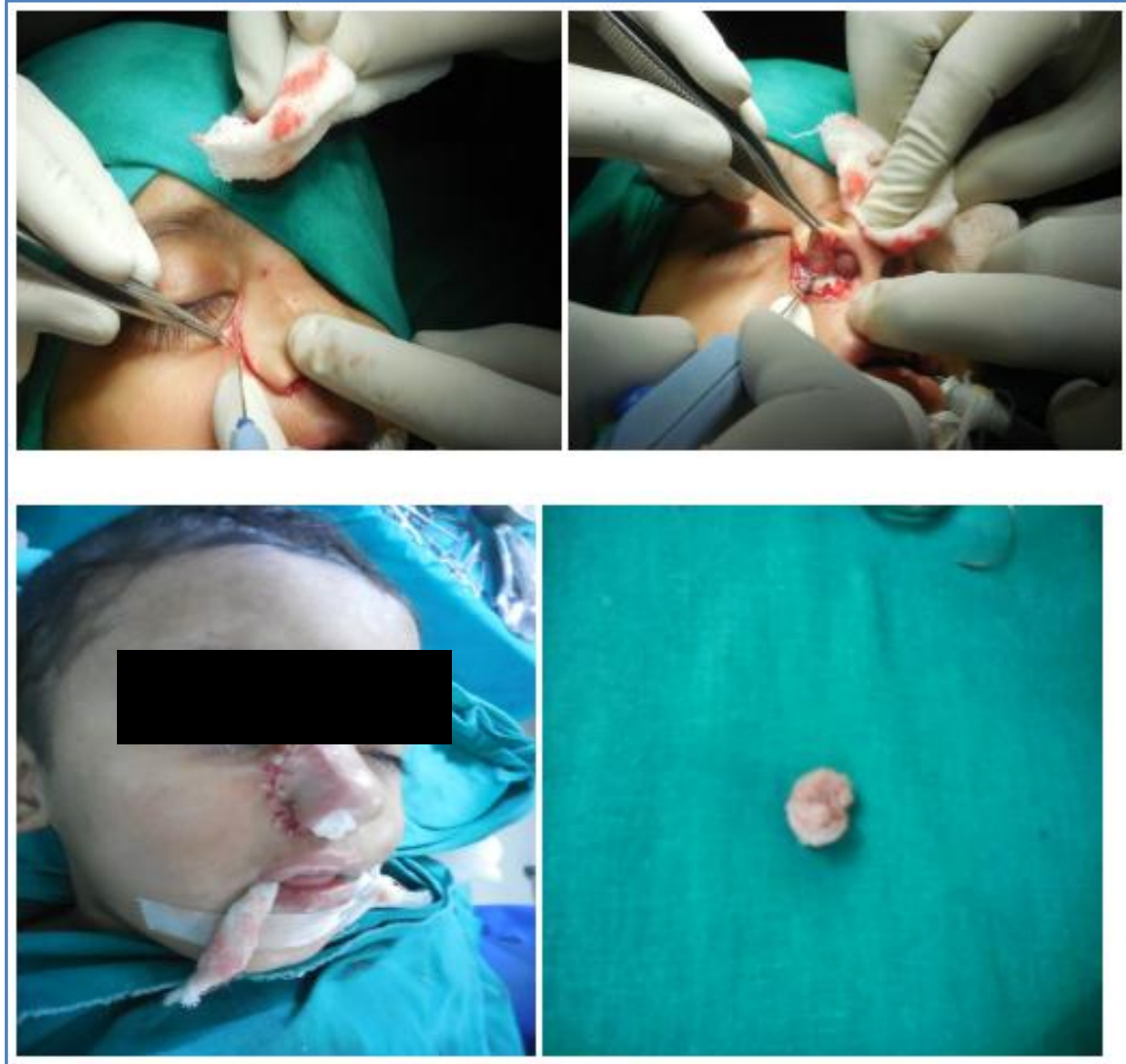

Fig. 3a, 3b, 3c \& 3d: Intra operative photos 


\section{CASE REPORT}
A: Lateral rhinotomy incision.
B: Intra operative tumor in the (R) Nasal cavity.
C: Incision after suturing.
D: Specimen.

Patient was taken up for surgery under general anesthesia through lateral rhinotomy approach, lateral rhinotomy incision is given on (R) side skin flaps elevated to expose the nasal cavity, the ala retracted, single grayish white globular mass attached to septum and lateral wall of the (R) nasal cavity, mobilized from all the sides and removed in toto and sent for HPE. Wound was closed in layers post op recovery was unevent ful, sutures removed on $7^{\text {th }}$ post op day, and discharged, patient is under follow up no recurrence seen after 08 months.

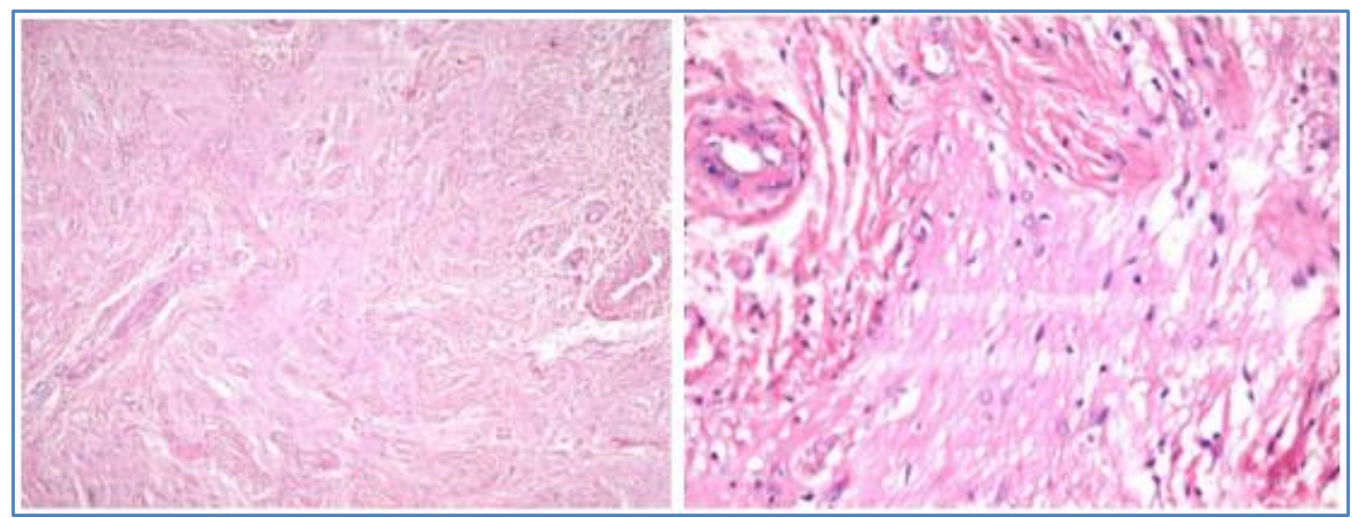

\section{Fig. 4: Nasal Glial heterotopia 10x H\&E Nasal} Glial heterotopia 40x H\&E. HPE Report

HPE Report (No.601/15) Serial sections show sinonasal surface epithelium with extensive squamons metaplasia. Subepithelial fibro collagenous tissue with few dilated sero-mucinous glands and ductal elements. These fibrous element is exuberant beneath the fibrous tissue is cartilage and neurovascular structures. There is sparse inflammatory infiltrate in the stroma.

S/o. Excuberent fibrous reaction. In view of recurrent nasal glioma, IHC GFAP is advised.

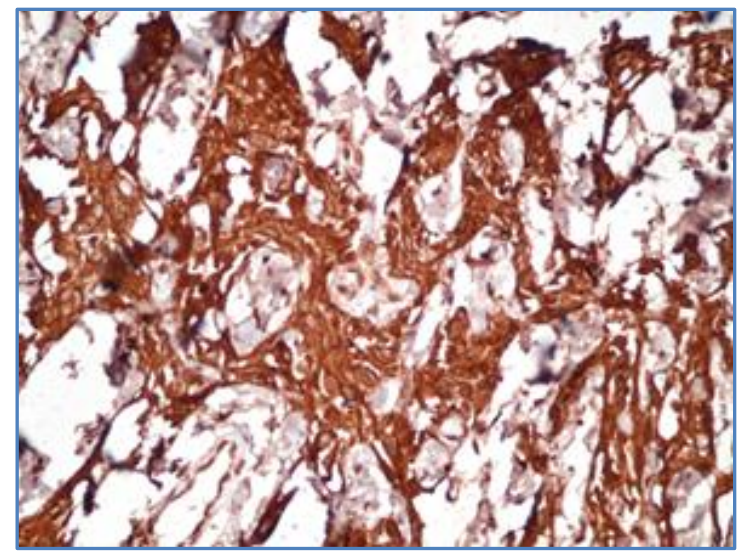

\section{Fig. 5: Nasal Glial heterotopia IHC-GFAP. IHC for GFAP}




\section{CASE REPORT}

IHC for GFAP (Glial fibrillary acidic protein) Report: GEAP - Focal cytoplasmic positivity, consider: Glial Heterotopy.

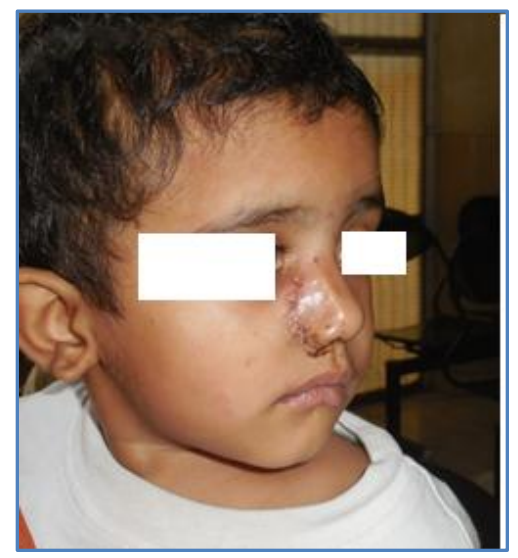

\section{Fig. 6: Post-operative photo after suture removal}

DISCUSSION: The term nasal glioma is a misnomer because such a mass is not a true neoplasm, nasal gliomas account for approximately $5 \%$ of all congenital nasal swellings, usually arise during infancy or later childhood with relative peaks of occurrence between 5 \& 10 years of age. The face develops during first 12 weeks of fetal growth, at the end of $2^{\text {nd }}$ week a small frontanelle is located between frontal and nasal bones, the nasofrontalis fonticnulus, during fetal development these spaces are normally closed by fusion. Abnormal development of these structures is thought to be involved in the formation of dermoids, gliomas and encephaloceles of the nose.

Developmental Theory Proposed as Ethiology: The possible theories of development of Nasal gliomas include.

1. Sequestration of glial tissue of the olfactory bulb entrapped during cribriform plate fusion.

2. Encephaloceles with lost intracranial and meningeal continuity.

3. Ectopic neural tissue cells.

4. In appropriate closure of the anterior neuropore (fronticulus forntalis). $(7,8)$

Clinically, these masses are firm in consistency, non-pulsatile, grayish, non-compressible lesions, these can protrude through the nostrils and can be confused with a nasal polyp. This patients may suffer from, nasal obstruction, CSF rhinorrhoea, epistaxis, epiphora, hypertolorism and cosmetic derformity.(9)

Radiological study normally confirms the nature of the mass, CT scan or MRI forms the mainstay of investigation as excision biopsy or FNAC carries a significant risk of meningitis or CSF leaks.(10)

On CT scan the mass is usually isodense to brain tissue.

On MRI, the lesion is isointense to hypo-intense relative to gray matter on T1-weighted sequences and hyper-intense on T2-weighted and photon density sequences. (9,11) $^{(9)}$

Histologically, nasal gliomas consist of unencapsulated rests of glial cells, predominantly astrocytes, embedded in varying amount of fibromuscular stroma(12,13,14) that may covered with skin 
or nasal respiratory mucosa, true capsule is absent and mistosis is rare, the glial nature of the cells can be further confirmed by immunohistochemical demonstration of S100 protein and GFAP.

The differential diagnosis of nasal gliomas includes several disorders, which can present as nasal masses.(15)

1. Nasal dermoids.

2. Encephaloceles

3. Hemangioma.

Nasal dermoids the most common congenital nasal anomaly and are cavities or sinus tracts possessing epithelial lining and variable number to skin appendages, encephaloceles which constitute the lesions caused by herniation of neural tissue through defects in the skull, hemangioma which are the most frequent benign vascular tumors in infancy.

The treatment of choice of nasal gliomas is complete surgical excision,(7) gliomas are benign but incomplete excision results in a $4 \%$ to $10 \%$ recurrence rate, the approach depends up on the location and extent of the lesion, which facilities are available, intra nasal endoscopic surgery is considered most appropriate approach for removal of intranasal glioma. Intranasal gliomas usually arise from the lateral nasal wall and can be approached via lateral rhinotomy approach. If an intracranial connection is found, a craniotomy or an external ethmoidectomy may be necessary.(15) Extranasal gliomas with no obvious CNS connection may be excised externally, using either a vertical elliptical midline incision or a horizontal incision over the dorsum of the nose.

CONCLUSSION: Nasal gliomas constitute one of the important midline nasal masses. It is mandatory to rule out intracranial extension by cross-sectional imaging preferable by MRI, surgical excision in the main stay of treatment, we are here describing a case of recurrent intranasal glioma operated by lateral rhinotomy approach, patient is under follow up at the time of presenting this paper.

\section{REFERENCES:}

1. Thomson HG al-Qattan MM. Becker LE. Nasal glioma: is dermis involvement significant? Ann plast Surg 34: 168-72. 1995.

2. Brown K. Brown OE. Congenital malformations of the nose. In: Cummings CW. Fredrickson JM. Harker LA. Krause CJ. Schuller DE. Richardson MA (eds). Otolaryngology Head and Neck surgery. $3^{\text {rd }}$ edition. Mosby year book. St. Louis, 1998. Pp: 92-103.

3. Congenital midline nasal masses, Grand Rounds presentation, UTMB, Deptt of otolaryngology, Nov. 62002.

4. Yeoh GP. Bale PM. De silva M. Nasal Cerebral Heterotopia: The so-called nasal glioma or sequestered encephalocele and its variants. Pediatr Pathol 9: 531-49. 1989.

5. Dini M. Lo Russo G. Colafranceschi M. So-called nasal glioma: case report with immunohistochemical study. Tumori 84: 398-402. 1998.

6. Paller AS, Pensler JM, Tomita T. Nasal midline masses in infants and children. Dermoids, encephaloceles, and gliomas. Arch Dermatol 1991: 127-362-6.

7. V. Nasa, V. Dejan, D. Dragan and J. Ljiljana, "Nasal glioma”, Archive of Oncology, vol. 14 no.1-2 pp. 57-59, 2006.

8. A.C.Swift and S.D. Singh, "The presentation and management of the nasal glioma", International journal of pediatric otorhinolaryngology, vol. 10, no. 3, pp. 253-261, 1985. 
9. S. K. Singhal, R. S. Virk, A. Dass, and S. Bansal, “Amanjit: neonatal nasal glioma: a case report,” Internet journal of Otorhinolaryngology, Vol. 4, p. 2, 2006.

10. P. Claros, R. Bandos, A. Claros, I. Gilea, A. Claros, and M. Real, "Nasal gliomas: main features, management and report of five cases," International journal of pediatric otorhinolaryngology, vol.46, no.1-2, pp. 15-20, 1998.

11. P.H. Jartti, A.E.Jartti, A. I. Karttunen, E.L. Paakko, R.L. Herva, and T.O. Pirila, "MR of a nasal glioma in a young infant,' Acta Radiologica, vol.43, pp. 141-143, 2002.

12. Fletcher CDM. Carpenter G. Mckee PH. Nasal glioma: A rarity. Am J Dermatopathol 8: 341-6, 1986.

13. Patterson K, Kaput S. Chandra RS. Nasal gliomas and related brain heterotopias: A Pathologist's perspective. Pediatrpathol 5: 353-62.1986.

14. Younus M. Coode P. Nasal glioma and encephalocele: two separate entities. J Neurosurg 64: 516-9, 1986.

15. Hengerer AS. Newburg JA. Congenital malfromations of the nose and paranasal sinuses. In: Bluestone CD. Stool SE. Scheetz MD (eds). Pediatric Otolaryngoloty. W.B. Saunders Company. Philadelphia. 2nd edition. 1990. Pp: 718-28.

\section{AUTHORS:}

1. D. Ranganath Swamy

2. K. Nagaraju

3. E. Yugandhar

4. B. Kathyayani

5. T. Shankar

\section{PARTICULARS OF CONTRIBUTORS:}

1. Assistant Professor, Department of ENT, Osmania Medical College, Hyderabad.

2. Assistant Professor, Department of ENT, Osmania Medical College, Hyderabad.

3. Resident, Department of ENT, Osmania Medical College, Hyderabad.

FINANCIAL OR OTHER COMPETING INTERESTS: None
4. Senior Resident, Department of ENT, Osmania Medical College, Hyderabad.

5. Professor, Department of ENT, Osmania Medical College, Hyderabad.

\section{NAME ADDRESS EMAIL ID OF THE} CORRESPONDING AUTHOR:

Dr. T. Shankar,

Flat No. 201, H. No. 12-5-149/6/A,

Sajja Ambience, Vijayapuri Colony,

Tarnaka, Hyderabad-500017,

Telangana State.

E-mail: drshankar_ms@yahoomail.com

Date of Submission: 20/07/2015.

Date of Peer Review: 21/07/2015.

Date of Acceptance: 04/08/2015.

Date of Publishing: 10/08/2015. 